\title{
Nursing students' experiences of patient safety incidents and reporting: A scoping review
}

\author{
Sherry Espin ${ }^{1}$, Nancy Sears ${ }^{2}$, Alyssa Indar* ${ }^{*}$, Lenora Duhn ${ }^{4}$, Karen LeGrow ${ }^{1}$, Binita Thapa ${ }^{1}$ \\ ${ }^{1}$ Ryerson University, Canada \\ ${ }^{2}$ St. Lawrence College, Canada \\ ${ }^{3}$ Humber College, Canada \\ ${ }^{4}$ Queen's University, Canada
}

Received: October 12, 2019

DOI: $10.5430 /$ jnep.v10n4p26
Accepted: December 9, 2019

URL: https://doi.org/10.5430/jnep.v10n4p26

\begin{abstract}
Background: Nursing students gain exposure to the realities of patient safety incidents (PSIs) during clinical placements. How students learn about PSIs and reporting within clinical placements remains to be explored.

Methods: This scoping review addressed: What is known about nursing students' understanding and experiences of PSIs and incident reporting while practising in a clinical setting? CINAHL, MEDLINE, Scholars Portal, and ProQuest Nursing and Allied Health databases were searched. Study selection and data extraction were conducted by two independent reviewers. Data were collated, summarized and reported narratively.

Results: Fifty-one articles were selected. Themes include: (1) types of PSIs reported; (2) how students engage in PSI reporting; (3) student factors related to PSIs; and (4) environmental factors relevant to student experiences of PSIs.

Conclusions: This scoping review provides a necessary foundation from which to build future studies, to best support students and educators in addressing safety incidents within a just culture paradigm.
\end{abstract}

Key Words: Scoping review, Patient safety incidents, Patient safety, Nursing students, Incident reporting

\section{BACKGROUND}

The seminal Institute of Medicine Report, ${ }^{[1]}$ To Err is Human - Building a Safer Health System, catalyzed the beginning of an international patient safety movement. However, nearly two decades later, we still grapple with how best to prevent patient safety incidents (PSIs). In a joint report by the Canadian Institute for Health Information (CIHI) and the Canadian Patient Safety Institute (CPSI) ${ }^{[2]}$ it is stated that an estimated one in 18 patients in Canadian hospitals experience a harmful, yet preventable PSI. More recent, additional Canadian findings further suggest $6 \%$ of admissions involve harm. ${ }^{[3]}$ Findings from other countries are equally concern- ing, with Makary and Daniel ${ }^{[4]}$ indicating medical error is the third leading cause of death in the United States. Although efforts to reduce PSIs have focused on the clinical practice settings, strategies must also be integrated into curricula for pre-licensure health professionals. This has implications for the nursing profession given nurses' integral roles in healthcare management and direct patient care, as well as being identified as the health professional most likely to be familiar with incident reporting - an essential mechanism for the determination and assessment of adverse events and their prevention. ${ }^{[5]}$

*Correspondence: Alyssa Indar; Email: alyssa.indar@gmail.com; Address: Humber College, Canada. 
Enhanced efforts are needed to integrate patient safety principles and incident reporting in baccalaureate nursing curricula. Students in all levels of nursing education programs are introduced to clinical environments through a range of clinical placements, across various settings. ${ }^{[6]}$ During placements, it is likely that student nurses will be exposed to unsafe practices or patient situations. Furthermore, students will work with health care professionals who may or may not report PSIs. ${ }^{[7]}$ It is critical that students learn strategies to manage the PSIs in which they are involved, continuously seek to improve patient safety, and consistently report any witnessed PSIs. It is imperative that these best, ethical practices are instilled during an individual's educational preparation in the hopes it is sustained throughout their professional nursing careers. However, more information is needed to understand the optimal type and timing of support to advance their learning about PSIs and patient safety generally.

Many patient safety educational interventions in the forms of simulation exercises and learning modules have been piloted. ${ }^{[8,9]}$ Importantly, these interventions occur in environments that are removed from the clinical practice setting. How students learn about and interpret patient safety within the context of clinical placements remains to be explored. Understanding the extant research about student incident reporting in the clinical context must be a first step before the development and evaluation of novel curricular strategies. Therefore, this scoping review addressed the question: From the current evidence, what is known about nursing students' understanding and experiences of patient safety incidents and incident reporting while practising in a clinical setting?

\section{MeTHODS}

Scoping reviews are useful when exploring the breadth and nature of the literature related to a guiding question. ${ }^{[10,11]}$ In this type of review, the researcher does not seek to assess the quality of the literature, but rather it is used as a necessary initial step in mapping the literature and identifying gaps related to methodology and content, in order to be best positioned before proceeding to future studies or informing decision-making. ${ }^{[12-14]}$ This review was guided by the methodological framework of Arksey and O'Malley, ${ }^{[12]}$ which includes the following steps: (1) identify the research question, (2) identify relevant studies, (3) select studies, (4) chart the data, and (5) collate, summarize and report results.

\subsection{Search Strategy}

After the development of the review question, an academic librarian was consulted to determine which databases to search and the strategies to refine the search terms. The databases used were: MEDLINE, CINAHL, ProQuest Nursing and Allied Health, and Scholars Portal. A variety of search terms were generated related to 'nursing students' and 'patient safety'. These terms were selected through the review of relevant literature, and refined in consultation with the academic librarian. The initial searches produced a combined total of 3,864 results.

\subsection{Identification of relevant studies}

The inclusion criteria for the articles were: (1) peer-reviewed; (2) study participants are undergraduate nursing students active in clinical placements; and (3) patient safety is the primary focus. Throughout the process, two reviewers (A.I. and B.T.) screened the articles and any disagreements were resolved through critical discussion. The titles and abstracts of the results were screened for relevance; after this review, 100 articles were selected for further examination. After removing duplicates, an in-depth full-text review, and excluding articles that did not meet the inclusion criteria at any phase in the process, a resulting 51 articles were included in the review (see Figure 1). Notably, articles were typically excluded if they not have a major focus on patient safety or nursing education. The seven removed during data extraction addressed patient safety in nursing education, but not within the context of a clinical placement.

Charting the data. A data extraction guide was developed based on the review question. The data was extracted from the selected articles and organized using a Microsoft Excel 2016 spreadsheet. The categories for the data extraction were derived from the preliminary literature review that was conducted, with the intention of quantifying the common aspects of the results of the studies. The category headings used were: article type, study methodology, country, student year, student placement, incident/error type, key finding(s), theory, tool(s) and implications.

Collating results and reporting. The process of collating and summarizing the study findings was guided by the principles of qualitative content analysis. This approach was useful to generate a description, rather than an interpretation of the data. ${ }^{[15,16]}$ The charted data were coded inductively and then reviewed in order to identify patterns and gaps. The codes were further grouped into categories and then reported as themes. These themes were organized in a logical scheme to facilitate clear reporting. This process was primarily undertaken by the same reviewers who screened the articles (A. I., B. T.). Both reviewers were involved in data extraction and therefore were familiar with the reviewed literature. The reviewers reviewed the final themes and engaged in critical dialogue to ensure that they were reflective of the data. 


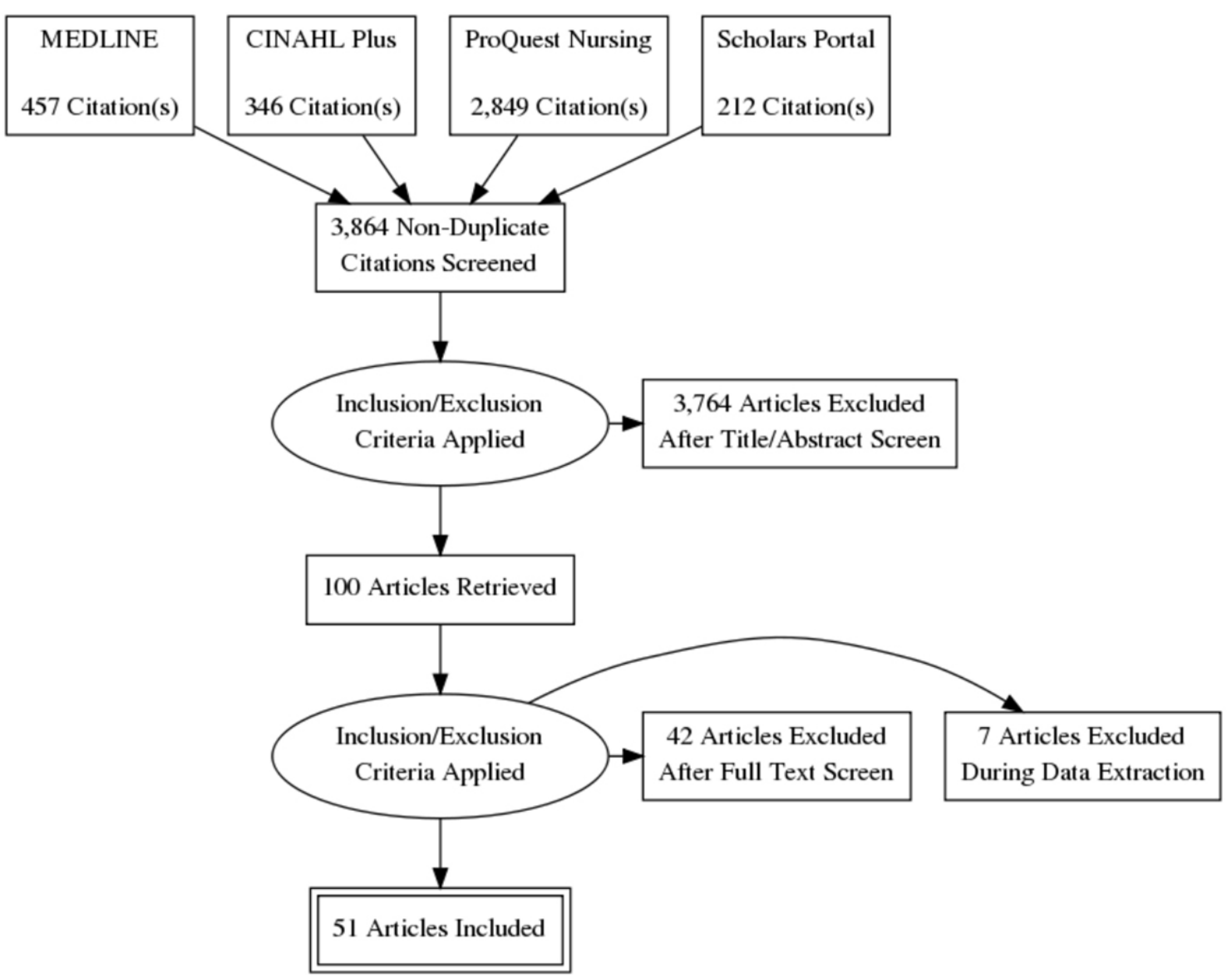

Figure 1. PRISMA Diagram

\section{Results}

Of the 51 articles selected for this review, the studies included quantitative, qualitative, and mixed methods designs, as well as literature reviews (see Table 1). Of the selected literature, 28 were quantitative studies, 13 were qualitative studies, four were mixed method studies and six were reviews of the literature. The studies were published from 2006 to 2019, and included articles of studies originating from 14 countries. In five of the studies, authors included the perspectives of individuals from non-nursing disciplines, such as pharmacy and medicine. ${ }^{[17-21]}$ In most of the studies, nursing student participants from multiple years of the nursing programs were examined. In nine studies, they only recruited final year nursing students. ${ }^{[21-29]}$

In many of the articles $(n=30)$, the authors did not specify the nature of the placements. For those authors who did, most of the placements were in acute care, hospital-based settings and represented specialties, such as medical-surgical care, critical care, pediatric care and maternal care $(n=19)$. The placements in long-term care $(\mathrm{n}=5)$, community care ( $\mathrm{n}$ $=7$ ) or mental health settings $(n=7)$ were described by authors in a few of the studies. In the reviewed literature, many researchers focused on PSIs about medication administration $(n=18)$, however all types of incidents were considered in this review.

\subsection{Themes}

Four themes emerged from the analysis of the literature: (1) types of reported incidents; (2) how nursing students engage in incident reporting; (3) student factors related to the incidents; and (4) environmental factors relevant to the students' experiences of incidents.

Types of incidents reported. Stevanin et al. ${ }^{[30]}$ described PSI incidence rates that were witnessed or reported by first, second and third year nursing students. Overall, students witnessed or reported 3.8 PSIs per 1000 days of training in a clinical setting and most PSIs were related to medication administration. ${ }^{[30]}$ Similarly, Santos ${ }^{[31]}$ found that students most often committed medication errors, but the largest proportion of PSIs were related to care implementation, which encompasses skills such as adhering to guidelines and knowledge application. In examining only medication errors, Walsh et al. ${ }^{[32]}$ reported the three most common error types, which were: (1) not administering a medication within 
the appropriate time frame, (2) administering the medication at the wrong time, and (3) inaccurately documenting medication administration.

Of the fourth-year nursing students interviewed in the ReidSearl et al. ${ }^{[25]}$ study, nearly one third of the students described involvement with a medication error or near miss; it is unclear if or how these incidents were reported. When upper year students were asked about incident involvement, nearly a quarter could not remember an incident. Of those who did, the most commonly described 'mistakes' were: mislabeling medication (20\%), the administration of the wrong medication (26\%), negligence during medication administration (20\%), and performing a procedure on the wrong patient (27\%). ${ }^{[33]}$ Medication error reporting occurred most often during medication preparation and administration, and were related to the wrong route, dose or lack of manual dexterity. ${ }^{[34]}$ Nursing students struggle with skills related to following procedures or interpreting policies, including medication preparation. ${ }^{[31,35]}$ Additionally, students described their involvement in medication errors of omission. ${ }^{[7,36]}$ Nursing students have also reported witnessing unsafe incidents by health professionals. ${ }^{[19]}$

Gregory and colleagues ${ }^{[37]}$ reviewed 154 documented unsafe events from nursing students representing various years within the program and most incidents were characterized as potential adverse events (30.52\%), whereas $12.34 \%$ of the events were categorized as errors. Deviation from aseptic techniques was a commonly reported error, ${ }^{[38,39]}$ with more than a quarter of the student responses related to breaches of infection control procedures. ${ }^{[40]}$

Nursing student engagement in incident reporting. Nursing students suggest that $80 \%$ of their medication errors are reported to their instructors. ${ }^{[41]}$ However, Cebeci and colleagues ${ }^{[38]}$ suggest the incident reporting rate among nursing students is quite low. Furthermore, Shanty and Gropelli ${ }^{[20]}$ found that student nurses believe errors and near misses are inconsistently reported to a staff nurse or preceptor. Information was not provided in these studies on how students used the organizational incident reporting system. Nursing students are also less likely to report errors that are not perceived as harmful to the patient to a staff nurse or preceptor. ${ }^{[7,20]}$

In the reviewed literature, there were discrepancies between estimated student reporting rates. Nursing students' intention to report medication errors was described as high. ${ }^{[42]}$ However, Palese et al. ${ }^{[43]}$ found that $41.7 \%$ of nursing students across years 'never', 'rarely' or 'sometimes' reported PSIs. Usher et al. ${ }^{[44]}$ clarified that the importance of reporting was rated more highly by third year students than by first and second year students. However, reporting rates and the meaning attached to reporting differed between students in different years of the nursing program. First time errors appeared to decrease over time spent in the program. ${ }^{[32]}$ Second year students were likely to view errors as a learning opportunity, whereas fourth year students perceived errors as a barrier to their learning. ${ }^{[31]}$

Despite good intentions to report errors, barriers exist to actual student reporting. Barriers include fear of negative consequences from nurses or faculty, ${ }^{[7,41-43,45]}$ administrative barriers such as a focus on individual rather than system factors, or no positive feedback for giving medication correctly ${ }^{[41]}$ high perceived workload, ${ }^{[46]}$ and other nurses' perceptions of the incident as unimportant. ${ }^{[7]}$ Koohestani and Baghcheghi ${ }^{[41]}$ found that the reporting process was the weakest perceived barrier.

Tella et al. ${ }^{[29]}$ found that allowing students to practise error reporting when they were in the clinical setting increased their comfort. Additionally, students stated that they were more likely to report a PSI if they were provided an opportunity to explain why the incident occurred and their feelings about the incident. ${ }^{[32]}$ Furthermore, students were more likely to report if they were provided with subjective feedback focused on improving their competence, rather than objective feedback focused on the error - an acknowledged divergent finding compared to others such as that of Koohestani and Baghcheghi. ${ }^{[41]}$ Noland and Carmack ${ }^{[47]}$ reported that students tended to communicate incidents in nonassertive, passive ways, instead of using assertive strategies.

Nursing students drew upon particular narratives when describing safety incidents, regardless of whether or not the incidents were reported. In either case, students were careful to portray themselves in a positive light. ${ }^{[33,48]}$ For example, to describe reported incidents, students cited personal factors, such as moral strength or professional commitment. ${ }^{[48]}$ Conversely, to describe unreported incidents, students highlighted external factors that hindered their ability to report. ${ }^{[48]}$ When describing witnessed incidents, students used three distinct narratives: experienced nurses as 'saving the day' due to their expertise; the 'silence' of the student and hospital staff in their lack of disclosure of errors to patients; and the unease that students feel when experts are observed making mistakes. ${ }^{[33]}$

Causes of incidents. According to Harding and Petrick, ${ }^{[49]}$ $79 \%$ of errors committed by nursing students could be attributed to system-level factors (e.g., order transcription errors, similar drug names) and not adhering to policies related to medication administration. Similarly, Valdez and colleagues ${ }^{[50]}$ found that lack of adherence to medication 'rights' had a direct effect on nursing student involvement in errors. 
Additionally, medication errors committed by students typically occurred during the busiest shift times, specifically during morning medication administration periods. ${ }^{[49]}$

Students believed they were the main contributor to error occurrence, specifically in regard to their stress, fear of failure, lack of attention, or limitations related to experience, managing activities and knowledge. ${ }^{[31]}$ Similarly, student deficits in performance, in which workload was a contributing factor, was noted as the most common cause of error. ${ }^{[36,38]}$ Students described additional causes for incidents, such as interpreting the PSI as a pharmacist's mistake or as an unimportant issue. ${ }^{[7]}$ In two studies, students perceived incidents and near misses to be caused by factors related to their environment, such as a busy work environment, increasing patient acuity, and pressure from nursing staff. ${ }^{[7,51]}$

Student factors. Many investigators described student attributes that informed perceptions of PSIs and behaviours related to reporting. The following five sub-themes highlight nursing students' perceptions, behaviours and characteristics related to PSIs and incident reporting.

Perceptions of patient safety incidents. Students express awareness that nursing care can be risky and that mistakes are inevitable. ${ }^{[52,53]}$ Bickhoff and colleagues ${ }^{[54]}$ state that students are aware of the potential to cause not just physical, but psychological harm to patients. Students report an awareness of their need to 'double-check everything' due to their lack of clinical expertise. ${ }^{[33]}$ However, students also describe a range of emotional responses when describing safety incidents or errors. Cooper ${ }^{[7]}$ reported that $60 \%$ of students are afraid to disclose errors. Disclosure was linked to fear of being punished or questioned. ${ }^{[4,45,55]}$ Nursing students described additional fears related to consequences, such as failing the educational program, not obtaining employment, and causing patient harm. ${ }^{[27,56]}$ Further, students struggle with applying medication safety principles within the clinical practice setting. ${ }^{[57]}$ Contextual factors, such as the lack of a nurse's oversight during clinical and being able to learn site-specific terminology, could further complicate students' abilities to apply learning related to patient safety. As a result, students drift between feeling worried and being careful. ${ }^{[57]}$

Emotional response to patient safety incidents. After witnessing errors, students used the following words to describe their feelings: "wrong, awful, inappropriate, uncomfortable, angry and...shocking" Monrouxe et al. ${ }^{[57]}$ (p. 509). Nursing students who contributed to a PSI reported feeling panicked and frustrated. ${ }^{[33]}$ Following the PSI, students associated PSIs with fear, guilt, shame and anxiety. ${ }^{[46]}$ Zieber and Williams ${ }^{[35]}$ emphasized the traumatic nature of the "mistake experience' for students and suggested that this stemmed from a lack of educational preparation and an inability to manage the consequences.

Confidence related to PSIs. Although student awareness of patient safety improves during a nursing program, there is a discrepancy between high confidence in the classroom setting and much lower confidence in the clinical setting. ${ }^{[58]}$ The decrease in confidence clinically could be due to difficulty in applying theory to practice and understanding the socio-cultural aspects of safety. ${ }^{[58,59]}$ Montgomery, Killam, Mossey, and Heerschap ${ }^{[60]}$ assert that students feel 'unsafe' in settings when they are unable to successfully integrate different types of knowledge into their practice. Interestingly, upper year students express difficulty in understanding the concepts of working in teams and systems thinking when applied clinically. ${ }^{[55,59]}$

Student growth in nursing program. Stevanin et al. ${ }^{[61]}$ found that first year students report confidence in their knowledge of patient safety principles; this confidence declines in year two, but returns by year three. It is not until completion of the first year in the program that students may begin to understand the complexity of safety, leading to decreased perceived competence; in later years, gaining autonomy may help students perceive themselves with a new confidence. ${ }^{[61]}$ Harding and Petrick ${ }^{[49]}$ found that medication error rates associated with nursing students declined with advancement in the program, specifically $39 \%$ of second year students reported a medication error, in contrast with $17 \%$ of fourth year students. Tabassum and colleagues ${ }^{[34]}$ described similar findings and clarified that more student-related medication errors seem to occur in medical-surgical placements rather than critical care placements. This may be explained by a higher proportion of upper year nursing students in critical care areas. $^{[34]}$

Nursing students' understanding of incidents seems to shift during their advancement in the program. Bogarin et al. ${ }^{[52]}$ describe third year students' understanding of incidents as related to procedural errors; in contrast, fourth year students attribute errors to a lack of team preparation or an unpredictable event.

Unsafe practice. Killam et al. ${ }^{[22]}$ described three themes common to students who displayed unsafe behaviours: (1) poor interpersonal skills, (2) low competence related to clinical knowledge and skills, and (3) lack of professional image. Mossey and colleagues (2012) posited a typology of fourth year students' characteristics, indicating that certain student types may be less safe for practice: (1) displaced students - those with track records of many errors and behaviours consistent with dishonesty and a lack of professionalism, 
(2) vulnerable students - those who feel overwhelmed, (3) unprepared students - those with less knowledge of safety guidelines, and with behaviours such as avoidance, and (4) distanced students - those socialized to 'cut corners' and who do not adhere to evidence-informed practice.

\section{Clinical environment factors.}

Environment. In a root cause analysis of a student medication error, a range of contributing environmental factors are highlighted, such as limited instructor availability, urgency conveyed by nurses, patient acuity, staff shortcuts, and lack of student familiarity with the clinical environment. ${ }^{[62]}$ Poor communication and punitive unit cultures were also emphasized. ${ }^{[62]}$

Supervision. Tabassum et al. ${ }^{[34]}$ identified that student medication errors occur when students without faculty supervision wrongfully administer medication. Although most students felt supported during medication administration, $66 \%$ specified that supervision levels were lower when the setting was busy, when the student was familiar with the setting, and when the nurses trusted the students. ${ }^{[63]}$ Ultimately, supervision can take a variety of forms depending on student competence, but supervision is suggested as a requirement to ensure patient safety. ${ }^{[25,26]}$ In the reporting of near misses, Gregory et al. ${ }^{[37]}$ specified that of the 47 'near miss' events reported, all were prevented by an instructor or staff nurse. Contextual factors that impeded the quality of student supervision were high workload, long clinical placements and nurse reliance on the student. ${ }^{[46]}$

\section{Discussion}

\subsection{Micro-, Meso-, and Macro-level Factors and PSIs}

In this review, it was identified that various factors contribute to students' experiences and perceptions of PSIs and incident reporting. Together, the themes illustrate how the interactions of various micro-, meso-, and macro-level factors are associated with student understanding and participation in PSIs. The micro-level factors are related to the individual student and include confidence in applying safety principles, and emotional responses to PSIs. The meso-level factors are reflected in descriptions of the clinical environments, in which 'busy' settings, staff attitudes toward safety, and the educators' support and management of incidents inform students' learning experiences. The macro-level factors describe barriers to incident reporting systems. The combination of these factors informs our understanding of nursing students' experiences of learning about PSIs and reporting within clinical settings.

Although the search strategy for this review was constructed to explore evidence to related to all types of PSIs, a finding

Published by Sciedu Press of this review was that a large subset of literature was related to nursing student involvement with medication errors. In two studies the authors referenced PSIs not related to medication errors, specifically infection control procedures. ${ }^{[37,40]}$ In the Hospital Harm Framework, ${ }^{[2]}$ harmful events are categorized into four types, each having significant influence on patient safety. While medication-associated PSIs figured prominently in the studies in this literature review, the other three types of events (health care-associated infections; patient accidents; and procedure-associated conditions) in the Hospital Harm Framework were investigated less frequently. This may be related to the fact that medication errors are known to be a high incidence, or highly reported, type of error.

Generally, it appears that nursing student incident reporting rates are relatively low, despite high levels of intention to engage in reporting behaviours. ${ }^{[41,42]}$ Low reporting rates could be attributed to barriers, such as fear of negative consequences and feeling too busy to report. These barriers suggest that harmful attitudes, influenced by instructor views or exposure to the clinical environment, could be informing students' understanding of safety. Additionally, there are system-level factors that impede the ability of students to apply their knowledge of patient safety in the clinical environment. ${ }^{[49,51,53,55]}$ Upper year nursing students report feeling confident about patient safety principles theoretically, but are less confident in its application related to teamwork and/or socio-cultural dimensions. ${ }^{[58]}$ This may be due to their increasing awareness about the risks inherent in clinical work, as well as greater interaction with staff in the clinical environment, who may not conceptualize safety in the same way.

A prominent theme related to the emotional responses of nursing students involved in PSIs was a sense of feeling 'awful'. Students may not be prepared to manage feelings of guilt and shame that can accompany a PSI. Patient safety educators could acknowledge the emotional experience of incident reporting, while emphasizing that incidents can occur due to human fallibility and system-level vulnerabilities.

\subsection{Nursing Education - Current Status and Future Considerations}

Despite receiving education related to patient safety, nursing students are uncertain about what to do when a PSI is encountered. Students struggle with interpreting policies and other actions related to care implementation. ${ }^{[31,35]}$ Training regarding incident reporting policies (including effective, accessible organizational reporting systems) could be helpful. Further, students have difficulty disclosing PSIs to faculty or clinical instructors. Augmenting the patient safety curricu- 
lum to include sessions on how to communicate incidents or practising incident disclosure and reporting could be beneficial.

Educating students about the expectations, importance, and requirement of reporting incident is the first step. ${ }^{[42,48]}$ Faculty can support students in reporting incidents, but also in being resilient after the incident occurrence. ${ }^{[34,35]}$ Offering suggestions for communicating mistakes may also prove beneficial. ${ }^{[64]}$ Faculty can provide students with safe learning spaces through the use of simulation scenarios in laboratory environments to practise prior to real-life clinical placements. ${ }^{[60,65]}$ Simulation for safe medication administration and incident reporting may be helpful in reinforcing these skills. ${ }^{[36]}$ A key component with these strategies is promoting open, honest and non-threatening conversations between students and educators. This type of communication promotes opportunities to provide feedback that is sensitive to how students feel and will help them to improve their practise. ${ }^{[32]}$

Nurse educators, clinical instructors and preceptors can cultivate patient safety cultures by supporting students in reporting incidents and building awareness of safety principles. ${ }^{[42]}$ Professional development for nurse educators can include tools to effectively guide and role model patient safety for nursing students. ${ }^{[45,60]}$

Implementation of more explicit patient safety education in the undergraduate curriculum may establish deeper patient safety knowledge and understanding prior to students entering clinical placements. ${ }^{[7,17,23,44,52]}$ The curriculum could include educating nursing students in addressing, anticipating, and managing safety risks by developing effective strategies. ${ }^{[20]}$ A curriculum could improve understanding related to patient safety principles and assist in minimizing incidents in clinical settings. ${ }^{[52]}$ The implementation of the principles of quality and safety education within the nursing curriculum has been suggested as a core component in the theoretical and clinical courses. ${ }^{[20,45]}$ Additionally, it may require us to consider the language we use related to PSIs, specifically the term 'error', especially if we are to embed a human factors approach to safety curriculums. ${ }^{[66]}$ We may need to be more sensitive and alert to the fact that while students will make mistakes, human factors and ergonomics principles helps us recognize the "inherent imperfections" within complex systems, wherein it is not possible to prevent all incidents, and we need to be assured as educators we are aware of and preparing students in appreciation of both of these circumstances (p. 2). ${ }^{[66]}$

Creating blame-free environments is important, so that a holistic, non-punitive view of incident analysis is estab- lished and incidents are evaluated systematically, rather than attributing errors to human failure. ${ }^{[7,41,45,50]}$ A closer look at the context highlights the importance of building a "just culture", in which accountability and transparency are paramount. ${ }^{[67]}$ Although typically referenced in relation to clinical settings, the shift toward a just culture can and should extend to nursing schools, wherein everyone has responsibilities (e.g., students must appropriately prepare for clinical and admit mistakes; educators must be apprised of current quality and safety principles and create safe learning environments for student incident disclosure; and organizational leaders must embed philosophies and processes reflective of a fair, just culture) and collaboration among students, faculty and organizational leaders is key (p. 44$){ }^{[68]}$ Recent work supports the inclusion of just culture principles in underpinning school policies that guide student incident reporting. ${ }^{69,70]}$ Students should be prepared in managing mistakes, both pragmatically from a procedural perspective (e.g., process and steps to reporting), as well as psychologically. ${ }^{[33]}$ This is important to prevent psychological harm, referred to as the second victim phenomenon. ${ }^{[71]}$ While further research is required in this regard, specific strategies could enhance communication, so students feel comfortable and confident in expressing safety concerns and disclosing. ${ }^{[35,64]}$

\subsection{Implications for research}

With the development of educational strategies, best practices, and through the recognition of existing barriers, students could be better positioned to practise patient safety principles. ${ }^{[17,20,45]}$ Exploring the relationship between patient safety education, and the type or setting of educational intervention, could be helpful in developing optimal strategies. ${ }^{[37]}$ Furthermore, examining the communication patterns between students involved in PSIs and their educators or staff nurses could identify communication gaps. ${ }^{[3,47,64]}$ Perspectives from educators and health professionals could provide a more comprehensive understanding of student involvement in PSIs and reporting. Additional insights could enhance understanding of the socialization process between students and preceptors ${ }^{[47]}$ and inform the nature of supervision necessary for the individual student learning needs. ${ }^{[27,62]}$ Incident reporting should be further explored within the nursing student population, as there was limited information in the literature regarding rates.

\subsection{Strengths and Limitations}

The study has timely information about students' experiences of PSIs and incident reporting, and was conducted in such a way as to ensure rigor and transparent results. A potential limitation is that all relevant literature might not have been captured in the search strategy, given that grey literature was 
not included, and only abstracts in English were included. As with all scoping reviews, which are designed to only map the literature, this review is intentionally limited to structured examination and summary of the extent, range and nature of current evidence, but serves as a precursor to potential future systematic reviews.

\section{Conclusion}

In this review, we have addressed the extent of the current literature related to nursing students' understanding and experiences of PSIs and incident reporting while practising in a clinical setting. The themes represented the types of incidents reported by nursing students, the ways in which nursing students engage in incident reporting, student factors, and the environmental factors relevant to the students' experiences of PSIs. This review was important in providing an initial 'landscape' of the current evidence, to now open the dialogue for considering and exploring in greater depth teaching-learning strategies in the classroom and clinical settings, regarding patient safety principles, attitudes and incident reporting procedures. Further, it has highlighted the need for additional research to understand the nature and prevalence of student involved patient safety incidents, incident disclosure and reporting across settings.

\section{CONFlicts of InTEREST Disclosure}

The authors declare that there is no conflict of interest.

\section{REFERENCES}

[1] Institute of Medicine and the Committee on Quality of Health Care in America. To err is human: Building a safer health system. Kohn, L. T., Corrigan, J. M., \& Donaldson, M. S. (Eds.). Washington, DC: National Academy Press; 2000.

[2] Canadian Institute for Health Information, Canadian Patient Safety Institute. (2016). Measuring patient harm in Canadian hospitals? Available from: https://secure.cihi.ca/free_products/c ihi_cpsi_hospital_harm_en.pdf

[3] Tessier L, Guilcher SJT, Qing Bai Y, et al. The impact of hospital harm on length of stay, costs of care and length of person-centred episodes of care: a restrospective cohort study. Canadian Medical Association Journal [Internet]. 2019 Aug [cited 2019 Sept 29]; 191(32): E879-895. PMid:31405834 https://doi.org/10.1503/cmaj . 1 81621

[4] Makary MA, Daniel M. Medical error - the third leading cause of death in the US. BMJ [Internet]. 2016 May [cited 2019 Sept 29]; 353: i2139. PMid:27143499 https : //doi .org/10.1136/bmj .i2139

[5] Mitchell I, Schuster A, Smith K, et al. Patient safety reporting: a qualitative study of thoughts and perceptions of experts 15 years after 'To Err is Human'. BMJ Quality and Safety. 2016 Feb; 25: 92-99. PMid:26217037 https : //doi .org/10.1136/bmjqs-2015-004 405

[6] Espin S, Meikle D. Fourth-year nursing student perceptions of incidents and incident reporting. The Journal of Nursing Education. 2014 Apr; 53(4): 238-243. PMid:24530013 https ://doi .org/10. 392 8/01484834-20140217-04

[7] Cooper E. From the school of nursing quality and safety officer: Nursing students' use of safety reporting tools and their perception of safety issues in clinical settings. Journal of Professional Nursing [Internet]. 2013 Mar [cited 2019 Sept 29]; 53(4): 238-243.

[8] Berndt J. Patient safety and simulation in prelicensure nursing education: an integrative review. Teaching and Learning in Nursing. 2014 Jan; 9(1): 16-22. https ://doi .org/10.1016/j.teln.2013.09 .001

[9] Cant RP, Cooper SJ. SImulation-based learning in nurse education: systematic review. Journal of Advanced Nursing. 2010 Jan; 66(1): 3-15. PMid:20423432 https : //doi .org/10.1111/j .1365-264 8.2009.05240.x

Published by Sciedu Press
[10] Grant MJ, Booth A. A typology of reviews: an analysis of 14 review types and associated methodologies. Health Information \& Libraries Journal. 2009 Jun; 26(2): 91-108. PMid:19490148 https://doi.org/10.1111/j.1471-1842.2009.00848.x

[11] Paré G, Trudel MC, Jaana M, et al. Synthesizing information systems knowledge: a typology of literature reviews. Information \& Management. 2015 Mar; 52(2): 183-199. https ://doi.org/10.1016/j . im. 2014.08.008

[12] Arksey H, O’Malley L. Scoping studies: towards a methodological framework. International Journal of Social Research Methodology [Internet]. 2005 Feb [cited 2019 Sept 29]; (1): 19-32. https : //doi.org/10.1080/1364557032000119616

[13] Olding M, McMillan SE, Reeves S, et al. Patient and family involvement in adult critical and intensive care settings: a scoping review. Health Expectations. 2016 Dec; 19(6): 1183-1202. PMid:27878937 https://doi.org/10.1111/hex.12402

[14] Tricco AC, Lillie E, O'Brien K, et al. A scoping review on the conduct and reporting of scoping reviews. BMC Medical Research Methodology [Internet]. 2016 Feb [cited 2019 Sept 29]; 16(15):1-10. PMid:26857112 https://doi.org/10.1186/s12874-016-011 6-4

[15] Elo S, Kyngäs H. The qualitative content analysis process. Journal of Advanced Nursing. 2008 Apr; 62(1): 107-115. PMid:18352969 https ://doi.org/10.1111/j.1365-2648.2007.04569.x

[16] Kahlke RM. Generic qualitative approaches: pitfalls and benefits of methodological mixology. International Journal of Qualitative Methods. 2014 Feb; 13(1): 37-52. https://doi.org/10.1177/1609 40691401300119

[17] Bianchi M, Bressan V, Cadorin L, et al. Patient Safety Competencies in undergraduate nursing students: a rapid evidence assessment. Journal of Advanced Nursing [Internet]. 2016 Dec [cited 2019 Sept 30]; 72(12): 2966. PMid:27222204 https://doi.org/10.1111/jan. 13033

[18] Milligan F, Wareing M, Preston-Shoot M, et al. Supporting nursing, midwifery, and allied health professional students to raise concerns with quality of care: a review of the research literature. Nurse Education Today [Internet]. 2017 Oct [cited 2019 Sept 30]; 57: 29-39. PMid:28711721 https://doi.org/10.1016/j.nedt.2017.06 .006 
[19] Monrouxe LV, Rees CE, Endacott R, et al. 'Even now it makes me angry': health care students' professionalism dilemma narratives. Medical Education [Internet]. 2014 May [cited 2019 Sept 29]. 48(5): 502517. PMid:24712935 https://doi.org/10.1111/medu. 12377

[20] Shanty JA, Gropelli T. Self-reported patient safety competence among nursing, respiratory care, and nuclear technology medicine students. Journal of Allied Health. 2018 Jul; 47(2): 141-146.

[21] Warholak TL, Queiruga C, ROush R, et al. Medication error identification rates by pharmacy, medical, and nursing students. American Journal of Pharmaceutical Education [Internet]. 2011 Mar [cited 2019 Sept 30]; 75(2): 24. PMid:21519414 https ://doi.org/10.568 8/ajpe75224

[22] Killam LA, Luhanga F, Bakker D. Characteristics of unsafe undergraduate nursing students in clinical practice: an integrative literature review. Journal of Nursing Education. 2011 Aug; 50(8): 437-446. PMid:21598859 https ://doi .org/10.3928/01484834-20110 517-05

[23] Langari MN, Tella S, Smith NJ, et al. Self-assessment of patient safety competence: a questionnaire survey of final year British and Finnish pre-registration nursing student. International Journal of Caring Sciences. 2017 Sept 10; 30: 1212-1223.

[24] Mossey S, Montgomery P, Raymond JM, et al. Typology of undergraduate nursing students' unsafe clinical practices: Q-methodology. Journal of Nursing Education [Internet]. 2012 Mar [cited Sept 30, 2019]; 51(5): 245-253. PMid:22390375 https ://doi.org/10.3 928/01484834-20120309-01

[25] Reid-Searl K, Moxham L, Happell B. Enhancing patient safety: the importance of direct supervision for avoiding medication errors and near misses by undergraduate nursing students. International Journal of Nursing Practice [Internet]. 2010 Jun 2016 [cited 2019 Sept 30]; 16(3): 225-232. PMid:20618531 https://doi .org/10.1111/j . 1440-172X.2010.01820.x

[26] Reid-Searl K, Moxham L, Walker S, et al. Shifting supervision: implications for safe administration of medication by nursing students. Journal of Clinical Nursing [Internet]. 2008 Oct [cited 2019 Sept 30]; 17(20): 2750-2757. PMid:18808644 https ://doi.org/10.1111/ j.1365-2702.2008.02486.x

[27] Reid-Searl K, Moxham L, Walker S, et al. Internal conflict: undergraduate nursing students' response to inadequate supervision during the administration of medication. Collegian [Internet]. 2009 [cited 2019 Sept 30]; 16(2): 71-77. PMid:19583176 https ://doi .org/ 10.1016/j.colegn. 2008.11.002

[28] Stomski N, Gluyas H, Andrus P, et al. The influence of situation awareness training of nurses' confidence about patient safety skills: a patient cohort study. Nurse Education Today [Internet]. 2018 Feb [cited 2019 Sept 30]; 63: 24-28. PMid:29407256 https : //doi.org/10.1016/j.nedt.2018.01.019

[29] Tella S, Smith N, Partanen P, et al. Learning to ensure patient safety in clinical settings: comparing Finnish and British nursing students' perceptions. Journal of Clinical Nursing [Internet]. 2015 Jul [cited Sept 30, 2019]; 24(19-20): 2954-2964. PMid:26216053 https://doi.org/10.1111/jocn. 12914

[30] Stevanin S, Causero G, Zanini A, et al. Adverse events witnessed by nursing students during clinical learning experiences: findings from a longitudinal study. Nursing \& Health Sciences. 2018 May; 20(4): 438-444. PMid:29771463 https://doi.org/10.1111/nh s. 12430

[31] Santos APS. Nursing students' errors in clinical learning. Qualitative outcomes in mixed methods research. Revista Brasileira de Enfermagem. 2019 Jan; 72(1): 170-176. PMid:30916283 https: //doi.org/10.1590/0034-7167-2018-0592
[32] Walsh LJ, Antsey AJ, Tracey AM. Student perceptions of faculty feedback following medication errors- a descriptive study. Nurse Education in Practice. 2018 Nov; 33: 10-16. PMid:30216803 https : //doi.org/10.1016/j.nepr.2018.08.017

[33] Noland CM. Baccalaureate nursing students' accounts of medical mistakes occurring in the clinical setting: implications for curricula Journal of Nursing Education [Internet]. 2014 Feb [cited 2019 Sept 30]; 53(3): S34-37.

[34] Tabassum N, Allana S, Saeed T, et al. Reported medication errors committed by undergraduate (four year bscn) students at akusonam, Karachi, Pakistan. International Journal of Nursing Education [Internet]. 2015 Jan [cited 2019 Sept 30]; 7(3): 94-98. https://doi.org/10.5958/0974-9357.2015.00142.7

[35] Zieber MP, Williams B. The experience of nursing students who make mistakes in clinical. International Journal of Nursing Education Scholarship [Internet]. 2015 May [cited 2019 Sept 30]; 12(1): 65-73. PMid:25951134 https://doi.org/10.1515/ijnes-2014-007 0

[36] Wolf ZR, Hicks R, Serembus JF. Characteristics of medication errors made by students during the administration phase: a descriptive study. Journal of Professional Nursing [Internet]. 2006 Jan [cited 2019 Sept 30]; 22(1): 39-51. PMid:16459288 https : //doi.org/10.1016/j.profnurs.2005.12.008

[37] Gregory D, Guse L, Dick DD, et al. What clinical learning contracts reveal about nursing education and patient safety. Canadian Nurse. 2009 Oct; 105(8): 20-25.

[38] Cebeci F, Karazeybek E, Sucu G, et al. Nursing students' medication errors and their opinions on the reasons of errors: A cross-sectional survey. Journal of the Pakistan Medical Association. 2015 May; 65(5): 457-462.

[39] Ozturk H, Kariman I, Bahcecik AN, et al. The malpractices of student nurses in clinical practice in turkey and their causes. The Journal of the Pakistan Medical Association. 2017 Aug; 67(8): 1198-1205.

[40] Geller NF, Bakken S, Currie LM, et al. Infection control hazards and near misses reported by nursing students. American Journal of Infection Control [Internet]. 2010 Dec [cited 2019 Sept 30]; 38(10): 811 816. PMid:20621394 https://doi.org/10.1016/j.ajic. 201 0.06 .001

[41] Koohestani HR, Baghcheghi N. Barriers to the reporting of medication administration errors among nursing students. Australian Journal of Advanced Nursing. 2009 Sept; 27(1): 66-74.

[42] Ben Natan M, Sharon I, Mahajna M, et al. Factors affecting nursing students' intention to report medication errors: an application of the theory of planned behavior. Nurse Education Today [Internet]. 2017 Aug [cited 2019 Sept 30]; 58: 38-42. PMid:28829995 https://doi.org/10.1016/j.nedt.2017.07.017

[43] Palese A, Gonella S, Grassetti L, et al. Multi-level analysis of national nursing students' disclosure of patient safety concerns. Medical Education. 2018 Nov; 52(11): 1156-1166. PMid:30345687 https://doi .org/10.1111/medu. 13716

[44] Usher K, Woods C, parmenter G, et al. Self-reported confidence in patient safety knowledge among Australian undergraduate nursing students: a multi-site cross-sectional survey study. International Journal of Nursing Studies [Internet]. 2017 Mar [cited 2019 Sept 30]; 71: 89-96. PMid:28364581 https ://doi.org/10.1016/j.ijnu rstu. 2017.03 .006

[45] Gropelli T, Shanty JA. Nursing students' perceptions of safety and communication issues in the clinical setting. Journal of Nursing Education [Internet]. 2018 May [cited 2019 Sept 30]; 57(5): 287-290. PMid:29718518 https ://doi .org/10.3928/01484834-20180 420-06 
[46] Asensi-Vincente J, Jiménez-Ruiz I, Vizcaya-Moreno MF. Medication errors involving nursing students: a systematic review. Nurse Educator. 2018 Sept; 43(5): E1-E5. PMid:29210898 https ://doi.org/ 10.1097/NNE.0000000000000481

[47] Noland CM, Carmack HJ. "You never forget your first mistake": nursing socialization, memorable messages, and communication about medical errors. Health Communication [Internet]. 2014 Nov [cited 2019 Sept 30]; 30(12): 1234-1244. PMid:25412245 https : //doi.org/10.1080/10410236.2014.930397

[48] Ion R, Smith K, Moir J, et al. Accounting for actions and omissions: a discourse analysis of student nurse accounts of responding to instances of poor care. Journal of Advanced Nursing [Internet]. 2016 Nov [cited 2019 Sept 30]; 72(5): 1054-1064. PMid:26768649 https://doi.org/10.1111/jan.12893

[49] Harding L, Petrick T. Nursing student medication errors; a retrospective review. Journal of Nursing Education [Internet]. 2008 Jan [cited 2019 Sept 30]; 47(1): 43-47. PMid:18232615 https: //doi.org/10.3928/01484834-20080101-05

[50] Valdez LP, de Guzman A, Escolar-Chua R. A structural equation modeling of the factors affecting student nurses' medication errors. Nurse Education Today [Internet]. 2012 Feb [cited 2019 Sept 30]; 33(3): 222-228. PMid:22325830 https://doi .org/10.1016/j . nedt. 2012.01.001

[51] Tabassum N, Saeed T, Dias JM, et al. Strategies to eliminate medication error among undergraduate nursing students. International Journal of Nursing Education [Internet]. 2016 Jan [cited 2019 Sept 30]; 8(1): 167-171. https://doi.org/10.5958/0974-9357.20 16.00030 .1

[52] Bogarin D, Barboza Zanetti AC, de Fátima Paiva Brito M, et al. Patient safety: knowledge of undergraduate nursing students. Cogitare Enfermagem. 2014 Jul; 19(3): 448-454.

[53] Yoshikawa J, Catin de Sousa BE, Sorgini Peterlini MA, et al. Comprehension of undergraduate students in nursing and medicine on patient safety. Acta Paulista de Enfermagem. 2013 Jan; 26(1): 21-29. https://doi.org/10.1590/S0103-21002013000100005

[54] Bickhoff L, Levett-Jones T, Sinclair PM. Rocking the boat - nursing students' stories of moral courage: a qualitative descriptive study. Nurse Education Today [Internet]. 2016 Apr [cited 2019 Sept 30]; 42: 35-40. PMid:27237350 https://doi.org/10.1016/j.nedt .2016 .03 .030

[55] Raymond J, Medves J, Godfrey C. Perspectives on patient safety among practical nursing students. Canadian Journal of Nursing Research [Internet]. 2016 Oct [cited 2019 Sept 30]; 48(2): 41-47. PMid:28841041 https://doi.org/10.1177/08445621166642 60

[56] Halperin O, Bronshtein O. The attitudes of nursing students and clinical instructors towards reporting irregular incidents in the medical clinic. Nurse Education in Practice. 2019 Mar; 36: 34-39. PMid:30851637 https://doi.org/10.1016/j.nepr.2019.02 .018

[57] Vaismoradi M, Jordan S, Turunen H, et al. Nursing students' perspectives of the cause of medication errors. Nurse Education Today [Internet]. 2011 May [cited 2019 Sept 30]; 34(3): 434-440. PMid:23669600 https://doi.org/10.1016/j.nedt.2013.04 .015

[58] Duhn L, Karp S, Oni O, et al. Perspectives on patient safety among undergraduate nursing students. Journal of Nursing Education [Internet]. 2012 Jul [cited 2019 Sept 30]; 51(9): 526-531. PMid:22766076 https://doi.org/10.3928/01484834-20120706-04
[59] Lukewich J, Edge DS, TRanmer J, et al. Undergraduate baccalaureate nursing students' self-reported confidence in learning about patient safety in the classroom and clinical settings: an annual cross-sectional study (2010-2013). International Journal of Nursing Studies [Internet]. 2015 Feb [cited 2019 Sept 30]; 52(5): 930-938. PMid:25698119 https://doi.org/10.1016/j.ijnurstu.2015.01.010

[60] Montgomery P, Killam L, Mossey S, et al. Third year nursing students' viewpoints about circumstances which threaten safety in the clinical setting. Nurse Education Today [Internet]. 2013 Oct [cited 2019 Sept 30]; 34(2): 271-276. PMid:24169443 https: //doi.org/10.1016/j.nedt.2013.09.019

[61] Stevanin S, Bressan V, Bulfone G, et al. Knowledge and competence with patient safety as perceived by nursing students: the findings of a cross-sectional study. Nurse Education Today [Internet] 2015 Apr [cited 2019 Sept 30]; 35(8): 926-934. PMid:25959704 https://doi.org/10.1016/j.nedt.2015.04.002

[62] Dolansky MA, Druschel K, Helba M, et al. Nursing student medication errors: A case study using root cause analysis. Journal of Professional Nursing [Internet]. 2013 Mar [cited 2019 Sept 30]; 29(2): 102-108. PMid:23566456 https ://doi .org/10.1016/j . profnurs.2012.12.010

[63] Reid-Searl K, Happell B, Burke KJ, et al. Nursing students and the supervision of medication administration. Collegian [Internet] 2013 Jun [cited 2019 Sept 30; 20(2): 109-114. PMid:23898599 https://doi.org/10.1016/j.colegn.2012.04.003

[64] Noland CM, Carmack HJ. Narrativizing nursing students' experiences with medical errors during clinicals. Qualitative Health Research [Internet]. 2014 Dec [cited 2019 Sept 30]; 25(10): 1423-1434 PMid:25539633 https://doi.org/10.1177/10497323145628 92

[65] Fagan A, Parker V, Jackson D. A concept analysis of undergraduate nursing students speaking up for patient safety in the patient care environment. Journal of Advanced Nursing [Internet]. 2016 Jun [cited 2019 Sept 30]; 72(10): 2346-2357. PMid:27221349 https://doi.org/10.1111/jan.13028

[66] Vosper H, Hignett S, Bowie P. Twelve tips for embedding human factors and ergonomics principles in healthcare education. Medical Teacher. 2018 Nov; 40(4): 357-363. PMid:29126356 https: //doi.org/10.1080/0142159X.2017.1387240

[67] Koller D, Espin S. Views of children, parents, and health-care providers on pediatric disclosure of medical errors. Journal of Child Health Care. 2018 Mar; 22(4): 577-590. PMid:29558835 https://doi.org/10.1177/1367493518765220

[68] Barnsteiner J, Disch J. Creating a fair and just culture in schools of nursing. The American Journal of Nursing. 2017 Nov; 117(11): 4248. PMid:29076855 https ://doi .org/10.1097/01 . NAJ . 00005 26747.84173 .97

[69] Disch J, Barnsteiner J, Connor S, Brogren F. Exploring how nursing schools handle student errors and near misses. The American Journal of Nursing. 2017 Oct; 117(10): 24-31. PMid:28914621 https://doi.org/10.1097/01.NAJ.0000525849.35536.74

[70] Penn CE. Integrating just culture into nursing student error policy. Journal of Nursing Education. 2014 Sept; 53(9): 107-109. PMid:25102128 https://doi .org/10.3928/01484834-20140 806-02

[71] Wu AW. Medical error: the second victim: the doctor who makes the mistakes needs help too. BMJ: British Medical Journal. 2000 Mar; 320(7237): 726. PMid:10720336 https ://doi .org/10.1136/bm j. 320.7237 .726 